\title{
ORNL/ER-155
}

Energy Systems Environmental Restoration Program

Clinch River Environmental Restoration Program

\section{Phase 1 Data Summary Report for the Clinch River Remedial Investigation: Health Risk and Ecological Risk Screening Assessment}

\author{
R. B. Cook, S. K. Holladay, S. M. Adams, L. A. Hook, J. J. Beauchamp, D. A. Levine, M. S. Bevelhimer,
} R. C. Longman, B. G. Blaylock, C. W. McGinn, C. C. Brandt, J. L. Skiles, C. J. Ford, G. W. Suter, M. L. Frank, L. F. Williams, M. J. Gentry

Date Issued--December 1992

Prepared by Environmental Sciences Division Oak Ridge National Laboratory ESD Publication 4021

Prepared for U.S. Department of Energy Office of Environmental Restoration and Waste Management under budget and reporting code EW 20

OAK RIDGE NATIONAL LABORATORY Oak Ridge, Tennessee 37831-6285 managed by MARTIN MARIETTA ENERGY SYSTEMS, INC. for the U.S. DEPARTMENT OF ENERGY under contract DE-AC05-84OR21400

\section{Executive Summary}

The Clinch River Remedial Investigation (CRRI) is designed to address The transport, fate, and distribution of waterborne contaminants from the U.S. Department of Energy's (DOE's) Oak Ridge Reservation (ORR) and to assess potential risks to human health and the environment associated with these contaminants. The contaminants released since the early 1940s include a variety of radionuclides, metals, and organic compounds. Primary areas of investigation are Melton Hill Reservoir, the Clinch River from Melton Hill Dam to its confluence with the Tennessee River, Poplar Creek, and Watts Bar Reservoir. The receiving river-reservoir system encompasses 140 river miles in length and 44,000 acres in surface area and is used for municipal water supply, sport fishing, navigation, boating, swimming, tourism, and residential development. The contaminants identified in the Clinch River/Watts Bar Reservoir (CR/WBR) downstream of the ORR are those associated with the water, suspended particles, deposited sediments, aquatic organisms, and wildlife feeding on aquatic organisms.

A phased remedial investigation of the CR/WBR system is underway to (1) define the nature and extent of the off-site contamination, (2) evaluate associated environmental and human health risks, and (3) preliminarily identify and evaluate potential remediation alternatives. The purpose of this report is to summarize the results of Phase 1 of the CRRI.

Phase 1 of the CRRI was a preliminary sampling and analysis of fish, sediment, and water in selected areas of the CR/WBR chosen to represent differing levels of media contamination. Specifically, Phase 1 ws designed to (1) obtain high-quality data to confirm existing historical data for contaminant levels in 
fish, sediment, and water from the CR/WBR; (2) determine the range of contaminant concentrations present in the river-reservoir system; (3) identify specific contaminants of concern; and (4) establish the reference (background) concentrations for those contaminants. Previously, scoping studies were conducted to provide an initial determination of contaminant distribution, in the sediments of Watts Bar Reservoir (Olsen et al. 1992) and to preliminarily assess potential human health and ecological risk (Suter 1991; Hoffman et al. 1991).

For Phase 1 of the CRRI, the CR/WBR system was divided into ten reaches, six of which are potentially affected by releases from the ORR. The other four reaches serve as reference areas. Contaminant concentrations for fish, sediment, and water were summarized for each of the 10 reaches. Analytes detected at least once in a reach were evaluated separately from those never measured above their analytical detection limit (i.e., nondetected).

In water samples collected during Phase 1, inorganic and organic constituents with the potential to pose a risk to human health or the environment were within the ranges reported previously in monitoring reports (e.g., Kornegay et al. 1991). Each inorganic contaminant detected during the Phase 1 investigation is well below the water quality criteria promulgated by the Tennessee Department of Environment and Conservation (rules of the Tennessee Department of Environment and Conservation, Chapter 1200-4-3).

The majority of potential contaminants of concern in Phase 1 water samples were detected between White Oak Creek and Poplar Creek on the Clinch River (reach 2) and in the Poplar Creek downstream of the confluence with East Fork Poplar Creek, which receive effluents from several ORR sources for these contaminants. Total copper and zinc were detected in reach 2 surface waters and had values in the range of those previously observed (Kornegay et al. 1991). Dissolved lead, observed in water samples form Poplar Creek upstream of the confluence with East Fork Poplar Creek, may originate from an upstream source.

The Oak Ridge Y-12 Plant, the city of Oak Ridge wastewater treatment facility, and Oak Ridge K-25 Site operations are among the possible sources for mercury, silver, and lead detected in water samples from Poplar Creek. Elevated levels of cadmium and lead in water samples from the Clinch River between Poplar Creek and the confluence with the Tennessee River may originate from several sources in and upstream from this reach.

Concentrations of all radiological constituents in Phase 1 water samples were within the ranges of those observed during environmental monitoring (Kornegay et al. 1991) and with previous scoping investigations (Olsen et al. 1992). Dissolved ${ }^{137} \mathrm{Cs}$ and particle-associated ${ }^{137} \mathrm{Cs}$ were detected in the Clinch River arm of Watts Bar Reservoir and Watts Bar Reservoir downstream of the confluence with the Clinch River, with values similar to those reported previously for these reaches. Dissolved ${ }^{137} \mathrm{Cs}$ was detected in Poplar Creek downstream of the confluence with East Fork Poplar Creek, possibly a result of backflow from the Clinch River. Cobalt-60 in Watts Bar Reservoir below the entry of the Clinch was detected at levels comparable with those reported previously. Average ${ }^{90} \mathrm{Sr}$ values for all reaches never exceeded drinking water standards. Each of these radionuclides is currently released in permitted discharges from the ORR to surface waters.

Data resulting from the measurement of inorganic, organic, and radiological contaminants from the Phase 1 water sampling, in combination with historical data, indicate that a focused characterization effort in Phase 2 is warranted for Poplar Creek downstream of the confluence with East Fork Poplar Creek and for the Clinch River arm of the Watts Bar Reservoir. Additionally, a more thorough 
characterization of reference sites is needed to rigorously establish background concentrations in surface water.

Concentrations of ${ }^{137} \mathrm{Cs}$ in surface sediments $(0$ to $10 \mathrm{~cm})$ in near-shore areas of Norris, Melton Hill Reservoirs, and the Tennessee River arm of Watts Bar Reservoir should represent background levels (\&lt1.0 pCi $/ \mathrm{g}$ ) because they are upstream of ORR and only received fallout from atmospheric testing of nuclear weapons. Concentrations in Poplar Creek and the Emory River average $1 \mathrm{pCi} / \mathrm{g}$, which is consistent with background concentrations. Cesium-137 concentrations in the near-shore surface sediments in the Clinch River arm of Watts Bar Reservoir are between 2 and $3 \mathrm{pCi} / \mathrm{g}$. Concentrations in Watts Bar Reservoir below the confluence of the Tennessee and Clinch rivers are usually less than 1 $\mathrm{pCi} / \mathrm{g}$, which are equivalent to background concentrations. Three areas within the Clinch River arm of Watts Bar Reservoir had concentrations between 10 and $34 \mathrm{pCi} / \mathrm{g}$ in surface sediment and will be targeted for sampling and analysis during Phase 2 of the CRRI. Samples collected at these areas will be analyzed for the contaminants identified by the risk screening as requiring further research.

Patterns of inorganic contaminants in sediment core samples indicate that there are multiple sources for these contaminants. Arsenic, beryllium, cadmium, chromium, copper, and mercury in Poplar Creek and the downstream portion of the Clinch River arm of Watts Bar Reservoir appear to be originating, at least in part, from Poplar Creek. Mercury releases from the Oak Ridge Y-12 Plant into the Poplar Creek system are well documented (Olsen et al. 1992, Turner et al. 1985). The other metals may be derived from disposal of coal fly-ash material and photographic processing chemicals from the Oak Ridge K-25 Site or from the municipal wastewater treatment facility for the city of Oak Ridge. Concentrations of cadmium, lead, and zinc are higher in the sediments in Watts Bar Reservoir below the confluence of the Tennessee River and Clinch River than elsewhere in the system, suggesting that there are sources of these contaminants to the Tennessee River arm of the reservoir or to WBR below the confluence of the two rivers. Phase 2 sampling and analysis will focus on locating any areas where concentrations of these contaminants pose an elevated risk to human health and the environment.

The lack of detectable quantities in sediment samples of most of the 92 organic chemicals for which analyses were conducted allows significant reduction in the list of organic contaminants requiring further study. Flouranthene, phenanthrene, and pyrene were found in Poplar Creek downstream of the confluence with East Fork Poplar Creek and in the Clinch River arm of the Watts Bar Reservoir. Aroclor 1254 was found only in sediments at Clinch River Mile 9.5, which is immediately downstream of Poplar Creek. Potential sources for these contaminants in sediment are ORNL, the Y-12 Plant, the K-25 Site, and the municipal wastewater treatment facility. Sampling and anaylsisfor these contaminants in Poplar Creek downstream of the confluence with East Fork Poplar Creek and in the Clinch River arm of Watts Bar Reservoir will continue in Phase 2 with the objective of identifying and delineating any areas requiring remediation.

Alpha-emitting radionuclides were detected in every site sampled for sediments. However, concentrations were all at or near background concentrations, except in Poplar Creek downstream of the confluence with East Fork Poplar Creek. Concentrations of ${ }^{234} \mathrm{U},{ }^{235} \mathrm{U},{ }^{238} \mathrm{U}$ in Poplar Creek sediments were above background levels. Poplar Creek downstream of the confluence with East Fork Poplar Creek will be the focus of study for these contaminants during Phase 2 activities.

In order to characterize the nature and extent of contamination in the biota of the CR/WBR system, 126 bluegill sunfish, 119 channel catfish, and 43 largemouth bass were sampled from 15 sites in 8 reaches. These fish species were chosen for sampling by virtue of their positions in the food web, their migration/mobility behavior, and relative availability. Of the 77 organic and 13 inorganic analytes, a 
majority (63 organics and 7 inorganics) were not detected $\mathrm{n}$ fish at any site. Of the radionuclides, only ${ }^{137} \mathrm{Cs},{ }^{60} \mathrm{Co}$, and ${ }^{90} \mathrm{Sr}$ were detected in fish. Four analytes were rarely detected, occurring in less than $5 \%$ of the samples, with only three of those $\left({ }^{90} \mathrm{Sr}\right.$, mercury, and zinc) detectable in all the samples.

In general, the Phase 1 maxima (individual maximum concentration of an analyte at each site) for fish are lower than those from previous sampling. Exceptions to this generality are mercury, selenium, and Aroclor 1260. Maximum values of mercury in fish collected in Phase 1 were higher than historical values only in lower Watts Bar Reservoir, and at no sites did the maximum mercury concentration exceed the Food and Drug Administration's (FDA's) action level of $1.0 \mathrm{mg} / \mathrm{kg}$. Selenium maxima in fish exceeded historical values in Poplar Creek downstream of the confluence with East Fork Poplar Creek and in the Clinch River upstream of Poplar Creek and below Melton Hill Reservoir. Aroclor 1260 (a PCB congener) maxima exceeded historical values in Poplar Creek downstream of the confluence with East Fork Poplar Creek and in the Clinch River below Poplar Creek. Average values of Aroclor 1260 in fish did not exceed $1.0 \mathrm{mg} / \mathrm{kg}$ at any site or within any reach, but Aroclor 1260 maxima in fish exceeded the FDA action level of $2.0 \mathrm{mg} / \mathrm{kg}$ at one site in Melton Hill Reservoir, one site in Poplar Creek, and three sites in the Clinch River arm of WBR.

Mean concentrations of some contaminants in fish at some CR/WBR sites were higher than the concentrations at the reference site (Norris Reservoir). Arsenic concentrations were significantly $(\mathrm{P}<$ 0.05) higher than concentrations at the reference site at only one location (CRM 0.5). In Poplar Creek below the confluence with East Fork Poplar Creek and at the first site downstream of the confluence of Poplar Creek and the Clinch River (Brashear Island), mercury concentrations in fish were predictably higher than those of the reference sites. Selenium concentrations in fish were higher than those in the reference site in main channel sites in the upper part of the system (Upper Melton Hill to Brashear Island). Zinc concentrations in fish at 5 of the 12 sites were higher than those at the reference site, but no obvious spatial distribution was evident. Chlordane concentrations in fish from Upper Melton Hill to the mouth of the Clinch River were higher than reference concentrations. Total PCB concentrations at all $\mathrm{CR} / \mathrm{WBR}$ sites were higher than those in fish from the reference site (Norris Reservoir). Cesium-137 levels for all fish species were usually higher than the reference, particularly below the confluence of White Oak Creek and the Clinch River. Concentrations of ${ }^{137} \mathrm{Cs}$ and mercury in fish are both elevated at sites downstream of known sources of these contaminants, White Oak Creek and East Fork Poplar Creek, respectively. No such patterns of downstream gradients of chlordane or PCBS in fish are evident.

A screening assessment of ecological effects in the CR/WBR was conducted concurrently with the health screening assessment. The ecological screening assessment considered potential toxic effects on aquatic biota due to exposure to contaminants in water, potential toxic effects to benthic and epibenthic organisms due to contaminants in sediment, and risks to piscivorous wildlife due to ingestion of contaminants in fish flesh. The assessment was performed by comparing chemical concentrations in media to screening benchmarks that are either regulatory criteria or concentrations that are estimated to hove minimal effects on the abundance or production of exposed populations. The screening ecological risk assessment for Phase 1 identified 14 contaminants of concern among the chemicals that were analyzed for and detected in water, sediment, or fish fillets. In addition, 19 chemicals that were not detected were identified as potential contaminants of concern because their limits of detection exceed screening benchmarks.

Comparison of media concentrations to toxicological benchmarks produced ambiguous results because of the large number of chemicals that were not detected but had limits of detection higher than potentially toxic concentrations. However, the number of potential contaminants of concern is much lower than in previous screening assessments because of generally lower contaminant concentrations 
than in the historical data, use of bioavailable (dissolved) concentrations of metals in water rather than total concentrations, and use of better screening benchmarks for metals in sediment.

A screening analysis using human health risk methodology similar to the approach used in Hoffman et al. (1991) to screen historical data was conducted with data collected during Phase 1 of the CRRI. The purpose of this screening exercise, along with the results obtained in Hoffman et al. (1991), is to help guide the development of the Phase 2 sampling plan, which will focus the collection of data on contaminants of concern. A future baseline risk assessment will be completed when data from the Phase 2 sampling are available.

Conservatively biased risk estimates were used to identify contaminants, exposure pathways, and river and reservoir reaches that have a low priority for further investigations. It is highly unlikely that these conservative estimates will underestimate the potential maximum exposure to an individual residing in the vicinity of the Clinch River where it receives releases of effluents from the ORR. Nonconservative estimates of risk were used to identify contaminants, pathways, and reaches that have a high priority for further investigation. These nonconservative estimates are more realistic than the conservatively biased estimates and should not substantially overestimate maximum exposures to local populations or subgroups.

The primary pathways examined were exposure to three media: fish, near-shore surface sediments, and surface water. Currently, there is not a realistic direct exposure pathway to deep sediment, where the highest concentrations of particle-reactive contaminants have been observed (Olsen et al. 1992). However, a dredging scenario was included in the screening analysis to evaluate potential exposure pathways if the sediment should be dredged and placed up on the shore. In addition to the direct exposure pathways from exposed sediment (ingestion and external exposure to radionuclides) included in the dredging scenario, secondary pathways were also considered (ingestion of meat, milk, and vegetables produced on dredged sediments). The dredging scenario depended on mathematical models to determine the concentration of contaminants in the agricultural products. Because the models are designed to increase the conservatism of the results, the dredging scenario was used only to identify contaminants of low priority for further investigation.

Nonconservative screening of data for the fish ingestion pathway identified Aroclor 1260, a carcinogenic $\mathrm{PCB}$, as a high-priority contaminant requiring immediate consideration for further investigation and potential remedial action for all reaches except reference reach 10 (Norris Reservoir). This contaminant was identified previously in Hoffman et al. (1991) as a high-priority contaminant. Other investigations have shown that PCBs contaminate most eastern Tennessee rivers and lakes, and although ORR is a probable source, it is not the only source of PCBs for the Clinch River and Tennessee River system. The Tennessee Department of Environment and Conservation has issued fish consumption advisories for several eastern Tennessee reservoirs (e.g., Fort Loudoun, Watts Bar, Melton Hill) as a result of PCB contamination.

None of the noncarcinogens that were analyzed in fish were identified as high priority contaminants. Conservative screening indicated that radionuclides $\left({ }^{60} \mathrm{Co},{ }^{137} \mathrm{Cs}\right.$, and $\left.{ }^{90} \mathrm{Sr}\right)$ found in fish sampled during Phase 1 could be assigned a low priority for future consideration in all reaches except for ${ }^{137} \mathrm{Cs}$ in the Clinch River arm of Watts Bar Reservoir. Conservative screening identified several carcinogens and noncarcinogens that had been identified previously (Hoffman et al. 1991) as requiring further investigation in fish (i.e., Aroclor 1254, chlordane, arsenic, beryllium, mercury, and selenium).

Nonconservative screening of the ${ }^{137} \mathrm{Cs}$ and ${ }^{60} \mathrm{Co}$ data from surface-sediment samples from near-shore 
areas did not identify these radionuclides as high priority contaminants. Conservative screening identified ${ }^{60} \mathrm{Co}$ and ${ }^{137} \mathrm{Cs}$, the only contaminants for which the samples were analyzed, as low priority in all reaches for the ingestion and inhalation pathways. In the external exposure pathway, ${ }^{137} \mathrm{Cs}$ was identified in Poplar Creek downstream of the mouth of East Fork Poplar Creek and in Melton Hill and Watts Bar Reservoir as contaminants requiring further investigation. However, Melton Hill Reservoir as contaminants requiring further investigation. However, Melton Hill Reservoir and the Tennessee River arm of WBR do not receive effluents from the ORR; therefore, the levels of ${ }^{137} \mathrm{Cs}$ found in the surface sediments of these reaches are background levels. A known source of ${ }^{60} \mathrm{Co}$ exists on the Clinch River upstream of the ORR, and it probably influences the screening indices for ${ }^{60} \mathrm{Co}$ in the Clinch River (Appendix G).

The results of the screening analysis for the water ingestion pathway should be viewed with caution because of the limited numbers of samples and because source monitoring data were used as estimates of concentrations in the reservoir. Thorium-228 was tentatively designated as a high priority contaminant in Poplar Creek downstream of the confluence with East Fork Poplar Creek in the water ingestion pathway. However, this designation results from including data from source monitoring sites. The monitoring data should be evaluated further before ${ }^{228} \mathrm{Th}$, which is a daughter of ${ }^{232} \mathrm{U}$ and naturally occuring ${ }^{232} \mathrm{Th}$, is designated a high priority contaminant. Screening of the water ingestion pathway showed Poplar Creek, which receives effluents from the K-25 Site and from the Y-12 Plant and the city of Oak Ridge west-end sewage treatment plant via East Fork Poplar Creek, has the greatest number of contaminants that require further investigation. In the other reaches, most of the contaminant values were below detection limits or are considered low priority for further investigation.

In the dredging scenario, conservative screening was conducted on two direct pathways-external exposure andingestion-and three secondary pathways-ingestion of meat, milk, and vegetables. Conservative screening of the secondary pathways identified many organic and inorganic contaminants in all reaches that could be assigned low priority for further investigation. Except for ${ }^{137} \mathrm{Cs}$ and to a lesser extent ${ }^{60} \mathrm{Co}$ and ${ }^{90} \mathrm{Sr}$, most radionuclides for which data were available were assigned low priority for the secondary pathways in all reaches.

Nonconservative screening was conducted for contaminants that had concentrations below analytical detection limits to identify contaminants for which either better analytical methodology is needed or for which source-term data are needed.

Results from Phase 1 of the CRRI indicate that Poplar Creek and the Clinch River arm of Watts Bar Reservoir are the reaches of greatest concern based on the number of contaminants that need further evaluation during Phase 2 of the remedial investigation.

The screening assessment of risk to the environment for Phase 1 indicates that cadmium, mercury and silver in water need to be further investigated to determine the risk to aquatic biota in the CR/WBR system, which may pose a risk to benthic swelling organisms, need to be further assessed during Phase 2 . More detailed sampling, analysis, and assessment are needed during Phase 2 of CRRI to conduct the baseline assessment for ecological risk.

For assessment of the risk to human health, the Phase 1 fish data are the most complete. The Phase 2 sampling for fish should concentrate on providing statistically valid data for a future baseline assessment for human health risk. Additional samples of water need to be collected and analyzed in surface water areas proximate to the ORR outfalls and sources to provide data for the baseline assessment of human 
health risk. Organic and inorganic contaminants common to eastern Tennessee and other metropolitan areas should be identified through further analysis of the available data for downstream and reference reaches. Analysis of organic contaminants in water and sediment should concentrate on those contaminants that are routinely released or have been released in the past from the ORR. The Phase 2 sampling and analysis should concentrate on previously identified contaminants in Poplar Creek downstream of the mouth of East Fork Poplar Creek and in the Clinch River arm of the Watts Bar Reservoir to provide statistically valid data for a baseline risk assessment.

ORNL Clinch River Environmental Restoration Program / The Visualization Group 